http://dx.doi.org/10.18232/alhe.938

Artículos

\title{
Argentina entre Nueva York y Londres, el financiamiento externo durante la primera guerra mundial
}

\section{Argentina between New York and London, the External Financing during the First World War}

\author{
Agustina Vence ${ }^{1, *}$ (DD 0000-0002-3059-5581 \\ ${ }^{1}$ Consejo Nacional de Investigaciones Científicas y Técnicas, Instituto Interdisciplinario de Economía Política, Buenos Aires, Argen- \\ tina. \\ * Correspondencia: agustina.vence@gmail.com
}

Resumen. Una de las características de la economía argentina hasta el estallido de la primera guerra mundial fue su relación con los mercados financieros europeos, particularmente con Londres. El inicio de la guerra alteró el funcionamiento de los mercados, desplazando el centro de las finanzas internacionales de Londres a Nueva York. Esto implicó buscar alternativas para financiar proyectos de obras públicas, así como negociar con un nuevo actor, lo que llevó a desarrollar nuevas relaciones financieras, con otros agentes financieros y un nuevo consenso político. El objetivo de este trabajo es analizar el vínculo entre Argentina y los mercados de Nueva York y Londres, con especial atención a las acciones de los grupos financieros europeos y norteamericanos, así como a las condiciones, mercados y formas en que el gobierno argentino tomó deuda, durante la primera guerra mundial.

Palabras clave: deuda pública; endeudamiento; financiamiento; intermediarios financieros.

Abstract. One of the main characteristics of the Argentine economy until the outbreak of the First World War was the strong relationship with European financial markets, particularly with London. The beginning of the war caused an alteration in the markets, and the displacement of the international finance center

CÓMO CITAR: Vence, A. (2019). Argentina entre Nueva York y Londres, el financiamiento externo durante la primera guerra mundial. America Latina en la Historia Económica, 26(1), e938. DOI: 10.18232/alhe.938 
from London to New York. This change involved finding alternative ways to finance public works projects, as well as negotiating with a new actor, which meant developing new financial relationships, with other financial agents and a new political consensus. The main objective of this paper is to analyze the link between Argentina and the New York and London markets, with special attention to the actions of European and North American financial groups, as well as the conditions, markets and ways in which The Argentine government took debt, during the First World War.

Key words: external debt; indebtedness; financing; financial intermediaries.

JEL: H63; H81; N26; N46.

Recibido: 1 de diciembre de 2017.

Aceptado: 16 de abril de 2018.

Publicado: 21 de junio de 2018

\section{INTRODUCCIÓN}

El estallido de la gran guerra produjo un cambio significativo en las fuentes de financiamiento de Argentina. En los años previos a 1914, como producto de la mejora en las condiciones de financiamiento y de la abundancia de capital externo, el gobierno emprendió una serie de obras públicas, particularmente en ferrocarriles hacia los territorios nacionales y obras de saneamiento en la ciudad de Buenos Aires. Hacia 1914, los contratos firmados con destino a las obras sanitarias alcanzaban los 40000000 de dólares y requerían un financiamiento de largo plazo que las condiciones de los mercados europeos no hacían factible (Regalsky, 2002; Vázquez, 1978). El gobierno intentó entonces una serie de negociaciones en Londres al cabo de la cual sólo se pudieron conseguir 5000000 de libras (aproximadamente 20000000 de dólares). Este fue el contexto que dio lugar a la intervención de un nuevo interlocutor: los bancos de la plaza de Nueva York.

En la primera década del siglo xx, el mercado de Nueva York había tenido escasa participación en los negocios de financiamiento público de los países sudamericanos. Los pocos títulos de la región que cotizaban en dicha plaza eran producto de que las principales firmas bancarias estadunidenses, City y Morgan, se habían asociado a sindicatos europeos, cuya conducción había estado generalmente a cargo de Baring Brothers. El gobierno argentino, acuciado por la imposibilidad de obtener el financiamiento necesario en Londres, inició negociaciones directas con bancos estadunidenses, que dieron lugar al primer préstamo de finales de 1914 con el National City Bank. Esta operación fue sucedida por otras de creciente magnitud entre 1915 y 1916, aunque siempre de corto plazo por la precariedad de la coyuntura internacional. A fines de 1916 el nuevo gobierno de Yrigoyen comenzó a avizorar la posibilidad de consolidarlas en un empréstito a largo plazo, pero la oposición en el Congreso, en una primera instancia, y luego el cambio de condiciones del mercado neoyorquino - con la entrada de Estados Unidos en el conflicto bélico- hicieron imposible concretar ese proyecto. Fue a partir de la crisis de 1920 que volverían a darse las condiciones para que se planteara la obtención de nuevos fondos externos, pero antes de eso, Argentina habría de terminar de reembolsar la última operación de crédito que mantenía, precisamente, con bancos de Inglaterra y Estados Unidos.

En este trabajo se busca revisar el derrotero seguido por estas negociaciones, y las cambiantes relaciones que involucraron actores de ambos mercados -el neoyorquino y el londinense- con el objeto de contribuir a esclarecer este aspecto central del impacto financiero y económico de 
la primera guerra mundial en Argentina, que también pretende aportar a las discusiones sobre la historia de las relaciones económicas argentino-estadunidenses, y la economía y finanzas del primer radicalismo. Para ello, se pondrá especial atención a la incidencia de los agentes financieros, y particularmente aquellos que ya operaban en Argentina en el periodo previo, en un contexto en el cual las firmas de la plaza de Nueva York carecían de redes propias de contacto ya establecidas para introducirse en este nuevo medio. El trabajo se ha basado en la consulta de una serie de fuentes correspondientes a las esferas oficiales argentinas, así como a los círculos financieros de las plazas involucradas (Londres, Nueva York), a los que se debe agregar el acceso a la correspondencia del Archivo Baring Brothers durante este periodo 1

\section{ESTADO DE LA CUESTIÓN}

El impacto de la gran guerra en Argentina ha sido un tópico abordado en la bibliografía más clásica. Muchos de los trabajos se han detenido en los aspectos económicos, señalando por ejemplo los efectos que la conflagración europea provocó en una economía abierta ante el repliegue del comercio internacional, los flujos migratorios y las inversiones externas (Di Tella y Zymelman, 1967; Ford, 1966) 2

En los últimos años hubo un renovado interés por el tema, poniéndose el acento en impacto social y cultural de la guerra en América Latina. Los trabajos de Stefan Rinke (2017) buscan romper con las periodizaciones que abarcan a la Gran Depresión y brindar una mirada global y/o regional al impacto de la guerra en Latinoamérica. Otros, tomando como punto de partida el desempeño de la opinión pública, echan luz sobre las afinidades culturales e ideológicas con los diferentes países beligerantes y la función de la prensa durante la guerra (Tato, 2008).

En lo que concierne a la esfera económica, algunos de los trabajos más clásicos han puesto el énfasis en los vínculos diplomáticos y comerciales durante la gran guerra. Al respecto destacan los trabajos de Tulchin (1990) y Peterson (1964), que abordan la política neutralista argentina durante la guerra, así como las presiones diplomáticas y económicas que recibió el país por parte de Estados Unidos, Gran Bretaña y Alemania.

En relación con la cuestión comercial, desde una mirada comparativa Albert (1988) confronta el caso argentino con el de otros tres países latinoamericanos cuyas economías también se estructuraron alrededor del modelo agroexportador. El autor plantea que los resultados inmediatos del conflicto no implicaron un quiebre en la línea de desenvolvimiento económico de los países analizados ni tampoco en lo que hace a su dependencia respecto de Europa. No obstante, desde su perspectiva, existió una ruptura al debilitarse la influencia comercial germana y de la hegemonía británica y el avance de los intereses estadunidenses, que continuaría durante la entreguerra en Latinoamérica. Sobre la relación comercial con Alemania y el Reino Unido, Gravil (1985) destaca el reforzamiento de los vínculos comerciales con los aliados, así como el establecimiento de controles sobre el comercio con América Latina. Por su parte Dehne (2009) analizó la estrategia británica de instalar las listas negras contra los intereses comerciales alemanes establecidos en Latinoamérica durante la contienda.

\footnotetext{
${ }^{1}$ Si bien no se ha podido lograr hasta ahora acceder a archivos de firmas estadunidenses, el de Baring Brothers brinda, como se verá, valiosos elementos sobre las relaciones entre esta firma y algunas de las más importantes de Nueva York que ayudan a entender la dinámica de la proyección de esas firmas en el mercado argentino.

${ }^{2}$ Tal vez el primero en referirse al tema haya sido Alejandro Bunge, desde las páginas de la Revista de Economía Argentina, a partir de 1918.
} 
Respecto a la integración de los mercados financieros en el siglo xx y su impacto en el crecimiento económico, Díaz (1970, p. 43) destaca que durante el periodo de la entreguerra se verificó una consolidación del mercado de capitales en Argentina. Al mismo tiempo, señala que, si bien durante la conflagración, Argentina comenzó a desplazar sus vínculos hacia el mercado de Nueva York, el flujo de capitales no fue tan pujante como el generado por Gran Bretaña entre 1900 y 1913. Por su parte, Taylor propone que la desintegración de los mercados mundiales fue una parte importante para explicar la retracción de las economías periféricas, puesto que el mercado de capitales local entre 1914 y 1939 fue débil (Taylor, 1997, p. 7).

Mientras que Díaz (1970) sostiene que la confianza crediticia argentina no era muy diferente a la de Australia y Canadá en los años veinte, Taylor señala el limitado acceso que tuvo Argentina al mercado de Nueva York, lo cual lo lleva a postular que generó una caída en la acumulación de capital (Taylor, 1992). Della Paolera y Taylor (2003, p. 169) por su parte, afirman que, en ausencia de ahorros externos, los menguantes déficits de la cuenta corriente significaron que Argentina debió financiar la mayor parte de su inversión doméstica con ahorro interno, sin que el sistema financiero local lograra responder adecuadamente a tal desafío. Por el contrario, Nakamura y Zarazaga $(1997$, pp. 1, 3) sostienen que durante la entreguerra Argentina se mantuvo firmemente integrada a los mercados financieros internacionales y que incluso su integración fue mejor en la década de 1920 que en el periodo previo a la guerra. Así, destacan que, si bien la colocación de deuda en los mercados europeos fue difícil, la colocación en el mercado doméstico y en Nueva York fue considerable (Nakamura y Zarazaga, 1997, p. 7). En un trabajo posterior Nakamura y Zarazaga (2001) examinan las fallas de las finanzas argentinas para llenar el vacío provocado por el declinamiento de Londres y del sistema financiero mundial durante la entreguerra. Según los autores, esto fue consecuencia del enorme peso adquirido por el Banco de la Nación Argentina, creando un desequilibrio en la estructura financiera (Nakamura y Zarazaga, 2001, p 3). Sostienen, al igual que Della Paolera y Taylor (1999), que la declinación de la banca privada en relación con el Banco de la Nación Argentina fue un componente crucial en la mediocre respuesta de la economía argentina a los desafíos planteados por la declinación británica (Nakamura y Zarazaga, 2001, p. 4) 3

Las primeras investigaciones sobre el impacto que tuvo el desplazamiento del centro financiero de Londres a Nueva York en el financiamiento argentino fueron realizadas en la década de 1930 por Harold Peters (1934) y Vernon Phelps (1938). Ambos autores destacaron que las relaciones entre Estados Unidos y Argentina para el periodo previo a la guerra eran casi insignificantes, aunque reconocían que antes de 1914 Estados Unidos había empezado ya a prestar atención al mercado argentino (Phelps, 1938). En su libro, Peters (1934) realiza un análisis pormenorizado de las emisiones en Estados Unidos para el periodo 1914-1930, destacando el poco conocimiento que tenía el inversor estadunidense de los mercados latinoamericanos -en especial de Argentinay cómo el estallido de la primera guerra llevó a un cambio en la actitud de los bancos de Nueva York respecto de la región. Peters (1934) adjudica relevancia a la apertura de la primera sucursal del National City Bank of New York, en Buenos Aires en 1914, y a la conformación del South American Group, sindicato bancario que tenía por finalidad concentrar los negocios financieros.

\footnotetext{
${ }^{3}$ No pueden dejar de mencionarse, en relación con este punto, los planteos de Marichal (2017) sobre la necesidad de estudiar con mayor atención la función de la banca y de las finanzas para entender mejor la evolución económica a largo plazo, e incluso de la propia evolución política, en los países de América Latina.
} 
En la década de 1980 la historiografía económica volvió a centrar la atención en la vinculación entre Estados Unidos y Latinoamérica. Stallings (1984, p. 64) plantea que los bancos estadunidenses comenzaron a interesarse en Latinoamérica por la expansión del comercio y las inversiones directas. Destaca que, antes de 1914, la legislación estadunidense prohibía la apertura de sucursales bancarias fuera del país y cómo, con la remoción de ese obstáculo a finales de 1914 - principalmente por los esfuerzos de Frank Vandelip del National City Bank- comenzó el acercamiento entre Estados Unidos y Argentina.

Marichal (1989) analiza el auge de préstamos estadunidenses a Latinoamérica en la década de 1920. Afirma que a pesar de que los bancos británicos siguieron manteniendo una actuación central en la región, se sintieron amenazados por el surgimiento de rivales que trataron de minar la primacía londinense ${ }^{4}$ Previamente, destaca que los banqueros de Estados Unidos habían avanzado de manera lenta pero progresiva formando parte de los principales sindicatos financieros internacionales que participaban en empréstitos sudamericanos antes de 1914. Los principales bancos de Nueva York como el National City Bank o J. P. Morgan \& Co., reconocían que, a pesar de las posibilidades de expandir sus negocios en la región, el público estadunidense era reacio, y que los banqueros europeos tenían mayor experiencia en ese campo (Marichal, 1989, pp. 171-172).

Sobre la participación de los merchant banks británicos en la colocación de títulos de deuda externa en el mercado de Londres, se destacan los trabajos de Flandreau y Flores. Los autores destacan que el prestigio y la reputación de esos intermediarios permitían afrontar los problemas de asimetría en la información de los mercados financieros (Flandreau y Flores, 2011). Los inversionistas dejaban la supervisión a los bancos encargados de la emisión de dichos títulos al contar con una relación directa con los gobiernos implicados (Flores, 2012, p. 13). Por lo tanto, la actuación del intermediario financiero era fundamental para el éxito de la emisión. Los bancos actuaban como proveedores de consejo e información a los inversionistas (Flores, 2012, p. 16). El prestigio también actuaba como estrategia de inversión al crear una barrera a la entrada de otros bancos.

Si bien el estallido de la primera guerra produjo un abrupto cambio en el sistema financiero, para Marichal (1989) el desplazamiento del centro financiero de Londres y Nueva York recién se consolidaría hacia 1920. Entre 1914 y 1918 los gobiernos latinoamericanos recurrieron a diferentes fuentes de financiamiento como, por ejemplo, los excedentes de su balance comercial o la financiación en el mercado interno (Marichal, 1989, p. 173). El cambio se produciría hacia 1921, cuando los gobiernos de la región comenzaron a explorar las posibilidades de financiamiento a largo plazo en la plaza de Nueva York, luego de la crisis de 1920-1921 (Marichal, 1989, p. 179). Respecto al financiamiento del gobierno argentino durante la primera guerra mundial, Regalsky y Salerno (2009) postulan que la guerra inició uno de los periodos más traumáticos en la historia fiscal. Destacan, a su vez, que lo singular de la experiencia argentina luego de 1914 fue la aparición de nuevas formas de financiamiento -en especial- en el mercado local tanto de corto y largo plazo, como en el mercado externo. Destacan que hasta fines de 1916 el papel principal en la financiación lo siguieron desempeñando los bancos extranjeros aportando casi $60 \%$ del total. Sin embargo, 40 \% fue asumido desde el inicio por el mercado local, mediante fuertes pedidos de adelanto a los bancos locales, principalmente el Banco de la Nación Argentina, y la emisión de

\footnotetext{
${ }^{4}$ Entre los principales bancos europeos que intentaron rivalizar con Londres se puede destacar el Disconto y el Deutsche Bank de Alemania, el Credit Mobilier y el Banque de París et des Pays Bas de Francia.
} 
Letras de Tesorería de corto plazo (Regalsky y Salerno, 2003, pp. 5-6). La cuestión del endeudamiento y las finanzas públicas durante la guerra y la entreguerra también ha sido trabajada de manera minuciosa por Cortés (2008).

Recientemente, varias investigaciones se han centrado en la conducta de los intermediarios financieros que operaron en el mercado de Nueva York durante el periodo de la entreguerra. Los trabajos sugieren que el deseo de construir y mantener el prestigio y la reputación de los intermediarios financieros fue determinante y que, los bancos líderes, preocupados por su prestigio, eran particularmente cuidadosos a la hora de suscribir un título (Flandreau, Gaillard y Panizza, 2010). Flandreau (2015) sostiene que el sistema londinense de las emisiones de deuda de países extranjeros fue trasplantado a Nueva York, y que la mayor transformación ocurrió mucho más tarde, con el establecimiento del New Deal y la ley Glass-Steagall[5]

\section{LAS FINANZAS EN LOS TIEMPOS RADICALES}

La guerra puso en evidencia las debilidades del modelo de crecimiento argentino y su extrema vulnerabilidad respecto del mercado internacional. De acuerdo con Tulchin (1990, p. 96), desde Buenos Aires se tardó mucho en apreciar que la guerra habría de modificar las relaciones de poder entre Estados Unidos y Gran Bretaña.

Para Gravil (1985, p. 112), el objetivo general de Inglaterra durante la guerra en América Latina fue asegurar la cooperación económica con los aliados como fuente de alimentos. La mayoría de los países latinoamericanos se mantuvieron neutrales. Durante la presidencia de De la Plaza, el gobierno se sintió tranquilo de que los países beligerantes tomarían en cuenta los intereses de Argentina, dada la importancia de sus exportaciones, sin considerar que la guerra implicara un corte abrupto con el pasado (Tulchin, 1990, p. 98). La elite argentina consideraba a la guerra como un fenómeno temporario al cabo del cual el mundo volvería a la normalidad y Argentina continuaría el curso ascendente del periodo previo (Tulchin, 1990, p. 104).

Con el ascenso al gobierno de Hipólito Yrigoyen (1916-1922) comenzó a apreciarse más cabalmente el impacto de la coyuntura internacional, por el cierre de los mercados de capitales y la fuerte reducción en el comercio internacional (Rayes, 2014). La estructura tributaria argentina descansaba en los aranceles aduaneros que gravaban las importaciones y, por ello, la caída de las importaciones tuvo un impacto negativo en los ingresos fiscales. Hasta fines de 1917 el nivel de los ingresos fiscales había caído $30 \%$ en términos nominales y 50 \% a valores constantes (Regalsky y Salerno, 2009, p. 209).

Ante la imposibilidad de reducir en la misma medida los gastos públicos, estos comenzaron a superar ampliamente a los recursos, generándose un déficit que sólo pudo ser afrontado con un aumento del endeudamiento público. En gran medida este déficit obedecía a la imposibilidad de reducir aún más los gastos administrativos ordinarios, ya que los gastos en obras públicas, con la excepción de los de obras sanitarias en 1914-1915, habían disminuido. Ya en el presupuesto de 1915 se había procurado no autorizar erogaciones que podían ser postergables, disponiéndose que los pagos por obras públicas afectadas por contratos y aquellas de carácter urgente se efectuaran con letras de tesorería. También se disponía la reducción de 10 \% de todos los gastos ordinarios, de

\footnotetext{
${ }^{5}$ Generalmente conocida como la Banking Act, entró en vigencia en junio de 1933. Introdujo diversas reformas en el sector bancario con el objetivo de controlar la especulación, destacando la separación entre la banca de depósito y la de inversión. Fue derogada en noviembre de 1999 por la ley Gramm-Leach-Bliley.
} 


\section{CUADRO 1. EVOLUGIÓN DE LOS INGRESOS Y EGRESOS DEL GOBIERNO ARGENTINO (EN MILLONES DE PESOS ORO)}

\begin{tabular}{lccc}
\hline Año & Ingresos & Egresos & Déficit/superávit \\
\hline 1913 & 163.2 & 117.5 & 45.4 \\
1914 & 124.2 & 184.6 & -60.4 \\
1915 & 111.4 & 176 & -64.6 \\
1916 & 112.2 & 164.8 & -52.6 \\
1917 & 111.9 & 171.4 & -59.5 \\
1918 & 145.2 & 185.3 & -40.1 \\
1919 & 180.9 & 188.3 & -7.4 \\
1920 & 228.4 & 214.6 & 13.8 \\
1921 & 205 & 246.5 & -41.5 \\
\hline
\end{tabular}

fuentes: Peters (1934) y Regalsky y Salerno (2009).

$75 \%$ en los subsidios para construcciones y de $50 \%$ en los otros (Soares, 1922, p. 61). Sin embargo, fue imposible reducir el gasto público en la medida necesaria, en parte por el contexto de alza de precios y por sus implicaciones sociales (Regalsky y Salerno, 2009).

Las medidas tomadas por el gobierno de Hipólito Yrigoyen persiguieron como objetivo compensar la disminución de los recursos tradicionales mediante la creación de nuevos gravámenes, o a través del aumento de las tasas de los ya existentes. A pesar de ello, se redujo también el gasto $20 \%$ en términos reales durante los dos primeros años de su gestión (Gerchunoff y Aguirre, 2006, p. 58). Gran parte de esa reducción recayó sobre la inversión pública: si en los años que precedieron a la guerra se ubicaba en alrededor de $15 \%$ del gasto público total, durante la posguerra y hasta mediados de los veinte permaneció comprimida a la mitad de ese valor (Gerchunoff y Aguirre, 2006, p. 58). La imposibilidad de hacer mayores ahorros obligó a continuar haciendo uso del crédito para cubrir los saldos de años anteriores y continuar las obras sanitarias y demás trabajos impostergables (Soares, 1922, p. 66). Apenas en 1920 se pudo lograr un pequeño superávit de las cuentas públicas (Regalsky y Salerno, 2009).

En cualquier caso, la necesidad de financiar este déficit fiscal en un contexto en el que por la guerra no se podía recurrir a los clásicos mercados europeos de emisión de títulos, dio lugar a la expansión de la deuda flotante. Parte del incremento de esta fue soportado por el mercado local, mediante fuertes pedidos de adelanto a los bancos locales, principalmente el Banco de la Nación Argentina (Regalsky e Iglesias, 2015), así como también, por la emisión de Letras de Tesorería entregadas como pago a contratistas y proveedores del Estado que también eran descontadas en los bancos locales (Regalsky y Salerno, 2009, p. 215). Por otro lado, el gobierno comenzó a colocar deuda a corto plazo en el mercado de Nueva York.

La deuda flotante entre 1913 y 1921 aumentó ocho veces. El aumento de la deuda a corto plazo en 1915 se debió, en parte, a la contratación de un préstamo por 50000000 de dólares, colocado a cinco años en Londres y Nueva York convirtiéndose en la mayor operación de su tipo durante el transcurso del conflicto bélico. La reducción en 1920 se debió al pago de dicho préstamo. Asimismo, la deuda externa consolidada desde el inicio de la guerra se reduce poco 


\section{GUADRO 2. EVOLUCIÓN DE LA DEUDA PÚBLICA NACIONAL (MILLONES DE PESOS ORO)}

\begin{tabular}{lccccc}
\hline Año & Deuda total & Deuda consolidada & Deuda externa & Deuda interna & Deuda flotante \\
\hline 1913 & 586.1 & 544.7 & 308.8 & 235.8 & 41.4 \\
1914 & 657.8 & 545 & 312.4 & 232.6 & 112.8 \\
1915 & 723.4 & 537.5 & 309.3 & 228.2 & 185.9 \\
1916 & 773.7 & 546.7 & 301.2 & 245.5 & 227 \\
1917 & 871.5 & 595.4 & 294.6 & 300.7 & 276.1 \\
1918 & 891.2 & 578.2 & 282.8 & 295.3 & 313 \\
1919 & 888.7 & 565.5 & 275 & 290.4 & 323.2 \\
1920 & 853.4 & 553.2 & 262.5 & 290.6 & 300.2 \\
1921 & 890.1 & 562.1 & 246.7 & 315.4 & 327.9 \\
\hline
\end{tabular}

Fuentes: Argentina. Departamento de Hacienda (1913-1921) y Regalsky y Salerno (2009).

a poco, por las amortizaciones y la falta de nuevas emisiones, producto del cierre del mercado financiero europeo y de la incapacidad de acceder al mercado de Nueva York con préstamos a largo plazo (véase cuadro 2).

De acuerdo con Tulchin (1990), el gobierno de Victorino de la Plaza, dentro de un marco de neutralidad, tuvo una actitud más proclive hacia Estados Unidos, que lo que mostraría Yrigoyen. A poco de iniciada la guerra, el ministro argentino de Relaciones Exteriores, José Murature $[$ encomendó al embajador en Washington, Rómulo Naón!7 realizar todos los esfuerzos posibles para estimular el comercio con Estados Unidos y alentar a su población a invertir sus capitales en el país (Tulchin, 1990, p. 98). Con la llegada de los radicales al poder Murature fue reemplazado por Carlos Becú 8 quien instruyó a Naón para desligarse de la Unión Panamericana liderada por Estados Unidos. De acuerdo con el autor, había sectores dentro del gobierno que veían con desconfianza una posible penetración del gran país del norte? 9

Es importante destacar que durante la presidencia de Yrigoyen se pensaba que Inglaterra permitiría que continuara el comercio con Alemania, porque no formaba parte de los intereses británicos lesionar el comercio argentino (Tulchin, 1990, p. 98). Gravil plantea que, hasta principios de 1916, los productos argentinos estaban casi libres de regulación, pero que luego se impuso una serie de controles para reservar las exportaciones argentinas para el consumo aliado, a pesar de la condición neutral del país (Gravil, 1985, p. 113). En marzo de 1916 los aliados establecieron listas negras que fueron extendidas a América Latina. Las compañías mencionadas en esas listas tenían

\footnotetext{
${ }^{6}$ José Luis Murature actuó como ministro de Relaciones Exteriores entre 1914 y 1916.

${ }^{7}$ Rómulo Naón fue ministro plenipotenciario en Estados Unidos entre 1910 y 1914 y posteriormente embajador en Washington entre 1914 y 1918. Durante toda su gestión fue un ferviente defensor de estrechar vínculos con este país.

${ }^{8}$ Carlos Becú fue ministro de Relaciones Exteriores entre octubre de 1916 y enero de 1917. Fue reemplazado por Honorio Pueyrredón, quien ocupó dicho cargo hasta 1922.

${ }^{9}$ Estados Unidos buscaba convertirse en el proveedor e inversor en América Latina, en reemplazo de los alemanes y británicos.
} 
prohibido utilizar bancos, transportes y comunicaciones británicos (Dehne, 2009). El gobierno consideró esta medida como una "interferencia ultrajante en los problemas internos argentinos" (Tulchin, 1990, p. 104).

Apenas llegado al poder, a fines de 1916 el gobierno de Yrigoyen solicitó en el Congreso la autorización para emitir un empréstito interno y/o externo a fin de consolidar la cuantiosa deuda flotante y dejar un remanente de fondos frescos para la financiación de las obras publicas. El proyecto no fue tratado, sufriendo el mismo destino de casi todas las iniciativas del poder ejecutivo en este periodo, en el marco de un fuerte conflicto de poderes. En 1917 se volvió a presentar en el marco de una importante propuesta de reforma financiera, pero nuevamente quedó sin ser tratado. No obstante, los excedentes comerciales y la abundante liquidez de la plaza local a partir de 1917, permitieron que la totalidad de los créditos externos (con excepción del bono de cinco años) fueran reembolsados, en gran medida con adelantos del Banco de la Nación Argentina. Así, gran parte del crecimiento de la deuda flotante fue soportado enteramente por el mercado local (Regalsky y Salerno, 2009).

La declaración de la guerra submarina en enero de 1917 tornó más difícil para el gobierno mantener la neutralidad. Por un lado, los alemanes hundieron tres barcos argentinos 10 y se supo que el ministro alemán Luxburg había calificado al canciller Pueyrredón como "un notorio idiota y anglófilo". Por el otro, Estados Unidos declaró la ruptura de relaciones con Alemania en febrero y en abril entraron en la guerra. Sin embargo, y pese a las presiones estadunidenses (Tulchin, 1990, p. 106), Yrigoyen continuó manteniendo la neutralidad. Para algunos, reflejaba sus posturas nacionalistas y antiimperialistas y su renuencia a aceptar presiones externas (Weinmann, 1994), mientras que, para otros, se enraizaba en sus principios pacifistas (Siepe, 1992).

\section{LOS PRIMEROS ACERCAMIENTOS AL MERCADO DE NuEVA YORK}

El estallido de la primera guerra y el cierre del mercado europeo, principalmente el de Londres, hizo que el gobierno argentino mirase al mercado de Nueva York como una fuente posible de financiamiento.

Por entonces el presidente Wilson convirtió en ley el Acta de la Reserva Federal que permitía a los bancos estadunidenses abrir filiales en otros países. En noviembre de ese año el National City Bank abrió su sucursal en Buenos Aires y en 1917 lo haría el Bank of Boston. La apertura de dichos bancos permitió un contacto más fluido entre el gobierno nacional y Estados Unidos en momentos en que Inglaterra restringía los préstamos a los países fuera del imperio. El gobierno argentino había contratado una serie de créditos para la consecución de obras públicas en los años previos a la guerra, que debían ser abonados o refinanciados. En diciembre de 1914, bajo la presidencia de Victorino de la Plaza (1914-1916) se realizó el primer préstamo con el National City Bank, conjuntamente con el Guaranty Trust Co. y Harris, Forbes \& Co. El monto fue de 15000000 de dólares a una tasa de $6 \%$, contra tres series de letras de tesorería, con vencimientos en 1915, 1916 y 1917. Esta emisión trajo alivio a las cuentas del Estado, puesto que los pagos a los contratistas y proveedores se realizaban con letras de Tesorería a seis meses.

${ }^{10}$ Los alemanes hundieron en abril el barco Monte Protegido, en junio el Toro y en julio el Oriana. 
En abril de 1915 se iniciaron nuevas conversaciones para la realización de un préstamo por 50 000000 de dólares por cinco años 11 El motivo era el vencimiento de un adelanto para las obras sanitarias que había sido contratado en Inglaterra por 8000000 de libras ${ }^{12}$ Los banqueros que habían otorgado el adelanto ofrecieron tomar la mitad a cinco años y el resto fue derivado a una serie de casas financieras de Estados Unidos con las que ya habían operado. ${ }^{13}$ Esas casas fueron J. P. Morgan \& Co., National City Bank, Kuhn, Loeb \& Co. y el First National Bank, mientras que Baring Brothers y Morgan-Grenfell \& Co. lo hacían por Londres. Esta sería la última operación en la que el sindicato londinense participaría hasta la década de 1920.

${ }^{11}$ The Wall Street Journal, 24 de abril de 1915.

${ }^{12}$ En 1913 el gobierno argentino había contratado dos créditos a corto plazo: por 5000000 de libras con la Baring y por 3000000 de libras con el London City and Midland Bank. Sobre la inversión en obras de saneamiento entre 1900 y 1930, véase Regalsky (2011).

${ }^{13}$ En las negociaciones de 1909 Estados Unidos solicitó el tratamiento en igualdad de condiciones que los europeos, véase Regalsky (2002). 


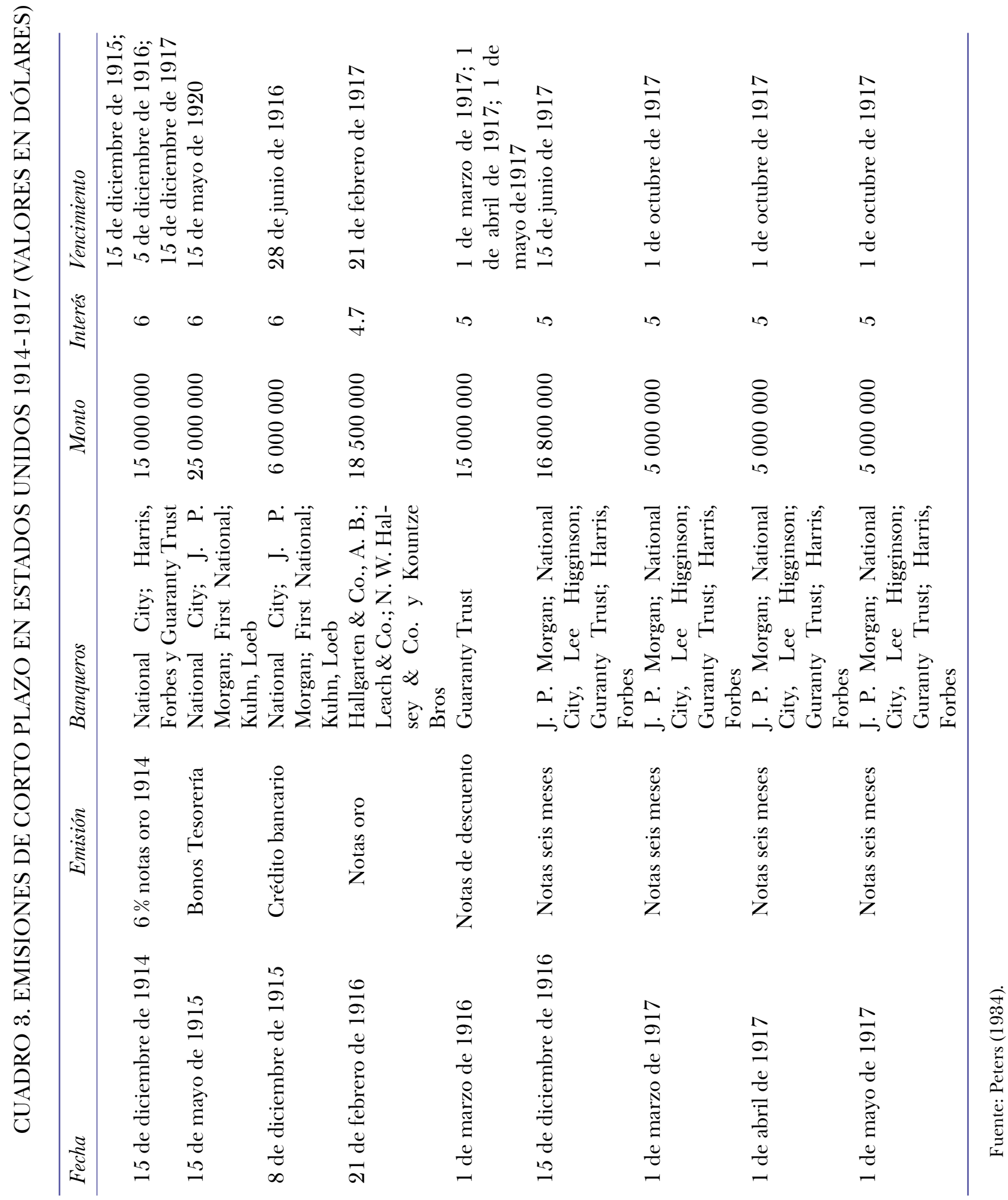


Según las publicaciones financieras de Nueva York, los miembros del sindicato estadunidense declararon que casi la mitad de la emisión había sido vendida y que las suscripciones recibidas habían sido satisfactorias 14

En el último año del mandato de De la Plaza (1915-1916), el ministro de Hacienda, Francisco Oliver, pudo colocar bastante deuda interna, y además puso en marcha un programa para que los déficits de presupuesto pudiesen ser absorbidos por los bancos locales hasta que mejoraran las condiciones para hacer una emisión a largo plazo a una tasa de 5 o $5.5 \%$ con objeto de consolidar la deuda flotante ${ }^{15}$ No obstante, a finales de 1915 vencía la primera serie del crédito contratado en 1914 por 5000000 de dólares. La decisión del gobierno fue contratar un préstamo de corto plazo con los principales banqueros de la plaza de Nueva York ${ }^{16}$ por 6000000 de dólares a 6 \% y con vencimiento en junio de 1916. Los fondos serían utilizados para el pago de los servicios de la deuda externa y de obligaciones corrientes, tal como se esperaba que al vencimiento el gobierno comenzaría negociaciones para un nuevo préstamo a mayor plazo 17

A pesar de los ajustes realizados por el gobierno nacional se tuvieron que emitir en el primer trimestre de 1916 dos préstamos de corto plazo, uno por 18500000 dólares a través de Hallgarten \& Co. a un año y otro por 15000000 de dólares con el Guaranty Trust Co. Este último, en tres series con vencimiento entre marzo y mayo de 1917. El National City Bank también ofreció al gobierno un préstamo por 15000000 que no fue considerado, probablemente porque sus condiciones fueran menos atractivas que los otros dos 18

Con el recambio presidencial y la llegada al gobierno de Hipólito Yrigoyen en octubre, 1916 se esperaba contar con la aprobación del Congreso para la consolidación de la deuda flotante. En el mes de diciembre -en sesiones extraordinarias- el poder ejecutivo envió varios proyectos de ley con este fin. Uno de ellos buscaba la autorización para contraer un empréstito externo o interno por la suma de 250000000 de pesos oro, a una tasa no mayor a $6 \%$ y una amortización no menor de $1 \%$ anual acumulativa. La intención del gobierno era consolidar las deudas a corto plazo, las letras de tesorería y los créditos pendientes, y que incorporara los vencimientos de 1917. El servicio de esta emisión se efectuaría con el producto de las obras sanitarias y con las generales de la nación. El segundo proyecto buscaba la autorización para emitir hasta 100000000 de moneda de curso legal o su equivalente en oro sellado en títulos de deuda interna o externa pública, que sería utilizado para la constitución del banco agrícola, la creación de la marina mercante y la explotación de los yacimientos de petróleo de Comodoro Rivadavia 19 A los pocos días de la presentación, la J. P. Morgan \& Co. le compró al gobierno la suma de 16800000 dólares en letras a seis meses a 5 \% de interés. Este dinero fue utilizado para pagar el vencimiento de la tercera serie de 1914, así como el crédito por 6000000 de dólares contraído en diciembre de 1915.

Un mes después de presentados los proyectos, ninguno había sido tratado por la Cámara de Diputados, por lo que el ministro de Hacienda solicitó que se tratara el tema con preferencia.20 Unos días más tarde, la Comisión de Hacienda de la Cámara de Diputados - por cuatro votos con-

${ }^{14}$ The Wall Street Journal, 12 de mayo de 1915.

${ }^{15}$ Sobre la emisión de letras de tesorería por parte del gobierno para hacer frente a sus compromisos de pago y la instauración del sistema de financiamiento denominado cauciones, véase Regalsky (2018).

${ }^{16}$ Los banqueros fueron National City Bank, First National Bank, J. P. Morgan \& Co. y Kuhn, Loeb \& Co.

${ }^{17}$ The Wall Street Journal, 21 de diciembre de 1915; Commercial and Financial Chronicles, 25 de diciembre de 1915.

${ }^{18}$ The Economist, 1916, pp. 191, 630.

${ }^{19}$ Diario de Sesiones de la Cámara de Diputados (en adelante DSCD), 11 de diciembre de 1916, p. 2791.

${ }^{20} \mathrm{DSCD}, 23$ de enero 1917 , p. 4450.

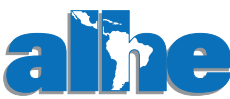


tra uno-footnoteLos votos a favor fueron de Marco. A. Avellaneda, Miguel M. Padilla, J. Cecilio López Buchardo y Prefecto Araya. Mientras que G. Martínez Zuviría lo hizo en disidencia. Véase DSCD, 26 de enero de 1917, p. 4621. aconsejó la sustitución de los proyectos enviados por el poder ejecutivo, por otro que autorizaba la emisión de hasta 265000000 de pesos oro. Para Marco Avellaneda, las autorizaciones solicitadas por el ejecutivo eran urgentes y necesarias ${ }^{21}$ Continuó su presentación aduciendo que si bien era cierto que el país necesitaba de los bancos estadunidenses para negociar su empréstito, ellos necesitaban un cliente como Argentina para colocar ventajosamente los enormes capitales disponibles ${ }^{22}$ Por su parte, Martínez Zuviria planteó que la comisión había observado el error de proyectar un empréstito a oro y el otro a pesos papel y por eso el despacho sólo autorizaba uno. Además rechazó la calificación de empréstito de consolidación puesto que no sólo se trataba de consolidar la deuda flotante, sino de costear obras públicas 23

Para marzo de 1917, casi tres meses después de haber sido presentado, el proyecto enviado por el poder ejecutivo no había sido aprobado. De modo que se lo retiró de la discusión y se cerraron las sesiones extraordinarias. El gobierno tuvo que abonar 23500000 dólares para reembolsar los primeros adelantos que vencían ${ }^{24}$ De acuerdo con las fuentes oficiales, el gobierno habría recibido varios ofrecimientos por parte de bancos estadunidenses para la contratación de un empréstito en condiciones favorables para el país (Argentina. Departamento de Hacienda, 1917, p. XIV). Para algunas publicaciones de la época, existía la posibilidad de que se negociara en Estados Unidos un gran préstamo para el pago de las obligaciones contraídas. En febrero, The Sun publicaba que el gobierno había logrado una ley que lo autorizaba a colocar un empréstito de consolidación en Estados Unidos, cosa que finalmente no había ocurrido. ${ }^{25}$ Ya para entonces, la crítica relación entre Estados Unidos y Alemania hacía imposible la colocación de un empréstito en la plaza de Nueva York ${ }^{26}$ En el mismo mes de febrero el gobierno tuvo que reembolsar el préstamo de Hallgarten \& Co. por 18500000 dólares luego de que fracasaran las negociaciones de renovación con dicha casa. ${ }^{27}$ Los fondos fueron obtenidos de las divisas disponibles en Estados Unidos a favor de Argentina ${ }^{28}$ A los pocos días vencía la primera cuota del préstamo del Guaranty Trust \& Co. El gobierno emitió notas a seis meses para su renovación con el South American Group, liderado por la J. P. Morgan \& Co. Dicha emisión no fue ofrecida al público y el gobierno esperaba que sucediera un arreglo similar con los próximos vencimientos ${ }^{29}$ Las notas de abril y mayo fueron renovadas por el mismo grupo y con vencimiento en octubre (véase cuadro 3 ).

Con la apertura de las sesiones ordinarias del Congreso, el 26 de junio de 1917, el gobierno volvió a enviar proyectos para la consolidación de la deuda flotante. Según el gobierno, varios grupos estadunidenses habrían presentado ofertas por montos y tasas de interés conveniente, pero

${ }^{21}$ DSCD, 26 de enero de 1917, p. 4621.

${ }^{22}$ DSCD, 26 de enero de 1917, p. 4623.

23 DSCD, 26 de enero de 1917, p. 4638.

${ }^{24}$ Entre febrero y marzo vencía el préstamo de Hallgarten y la primera serie del Guaranty Trust.

${ }^{25}$ The Sun, 16 de febrero de 1917. Es importante destacar que el proyecto del ejecutivo donde solicita la autorización para emitir deuda se presentó el 11 de diciembre y se les aseguró a los banqueros que la legislación se obtendría a finales de enero de 1917.

${ }^{26}$ The Economist, 1917, p. 588.

27 The Wall Street Journal, 8 de febrero de 1917.

${ }^{28}$ The Sun, 21 de febrero de 1917; Commercial and Financial Chronicles, 24 de febrero de 1917.

${ }^{29}$ Commercial and Financial Chronicles, 19 de marzo de 1917.

${ }^{30}$ Commercial and Financial Chronicles, 31 de marzo de 1917; New York Tribune, 1 de mayo de 1917. 
las condiciones internacionales no permitían la firma de contratos ad-referéndum ${ }^{31}$ Finalmente, la participación de Estados Unidos en la guerra impidió la reanudación de las negociaciones y el gobierno debió recurrir a la banca local para el pago de la deuda flotante (Argentina. Departamento de Hacienda, 1917, p. xxv). En junio vencía un préstamo de J. P. Morgan \& Co., que en parte fue renovado por 90 días y el resto pagado con depósitos argentinos en Nueva York ${ }^{32}$ Según el Commercial and Financial Chronicles, uno de los banqueros anticipaba que estos préstamos serían liquidados pronto puesto que, para ese momento, el balance comercial era favorable a Argentina. Por otro lado, informaba que Argentina estaba trabajando en un plan para reducir las necesidades de préstamos en el exterior mediante una gran emisión interna. ${ }^{33}$ Así, la deuda interna pasó de 245000000 de pesos oro a 300000000 entre 1916 y 1917 (véase cuadro 2).

En el mes de septiembre el gobierno pagó, a través del Banco de la Nación Argentina, las notas que habían sido renovadas en junio con el grupo Morgan. De este modo, las obligaciones del gobierno en Nueva York quedaban reducidas a 20000000 de dólares, de los cuales 15000000 vencían en octubre y 5000000 en diciembre. El crédito del país en el mercado estadunidense era bueno, pero los banqueros apuntaban que cualquier nuevo adelanto al país debía ser realizado con la aprobación del gobierno de Estados Unidos ${ }^{34}$ Para finales de año se terminaron de pagar los préstamos a corto plazo en Nueva York. De esta forma, quedaban canceladas las obligaciones contraídas en Estados Unidos desde el inicio de la guerra.

La fuerte posición acreedora de Argentina en el mercado de cambios, tanto con Estados Unidos como con Inglaterra y Francia llevaría a efectuar un préstamo a estos dos últimos países por 200000000 de pesos oro durante 1918 y 1919, así como a mantener depositado su superávit cambiario en Estados Unidos, para evitar que se apreciara aún más el peso frente al dólar. El préstamo fue negociado en los últimos meses de 1917 y firmado en el mes de diciembre. Según se informaba, su vigencia sería por dos años y sería progresivamente cancelado por el pago de los intereses de los préstamos que el país tenía con estas naciones, incluyendo el préstamo de 5000 000 de libras con la Baring que vencía en 1920 35

En 1919 el gobierno de Yrigoyen apoyó la realización de un Congreso Panamericano en Estados Unidos y envió como delegado al ministro de Hacienda, Domingo Salaberry. Varios periódicos plantearon que el viaje del ministro era para negociar un préstamo que permitiera afrontar el vencimiento en 1920 del préstamo contratado en $1915{ }^{36}$ Por su parte, The Economist publicó que grupos financieros estadunidenses le habían ofrecido al gobierno 300000000 de dólares. ${ }^{37}$ Según la prensa estadunidense, Salaberry contaba con el poder para realizar un acuerdo ad-referendum por 300000000 de pesos oro. Ricardo Aldao, uno de los participantes de la delegación argentina, había comentado en varias conferencias privadas en el marco de la conferencia panamericana que se había tratado la cuestión de la provisión de fondos para el vencimiento de 192038

${ }^{31}$ Los contratos ad-referéndum, requerían que los compromisos contraídos fueran validados por el Congreso.

${ }^{32}$ Commercial and Financial Chronicles, 23 de junio de 1916, New York Tribune, 13 de septiembre de 1917.

${ }^{33}$ Commercial and Financial Chronicles, 23 de junio de 1917.

${ }^{34}$ The Sun, 15 de septiembre de 1917.

${ }^{35}$ The Economist, 1918, p. 8.

${ }^{36}$ Commercial and Financial Chronicles, 14 de febrero de 1920; The Economist, 1920, p. 145.

${ }^{37}$ The Economist, 1920, p. 145.

${ }^{38}$ Commercial and Financial Chronicles, 18 de marzo de 1920. 
De acuerdo con las fuentes, el 17 de marzo de 1920 Salaberry se reunió con un grupo de banqueros en las oficinas de la J. P. Morgan y comentó la intención del gobierno de renovar la mitad del préstamo de 50000000 que vencía en el mes de mayo, pero aclarando que si los banqueros recomendaban su pago completo estaría dispuesto a hacerlo 39 The Economist publicaba que la recepción de la propuesta del ministro argentino, tanto en Washington como en Nueva York, había sido desalentadora, y que para los banqueros el préstamo debía pagarse por completo puesto que la balanza comercial entre Estados Unidos y Argentina era favorable para esta última ${ }^{40}$ En esta misma línea, el Commercial and Financial Chronicles afirmaba que Argentina podía pagar fácilmente el préstamo ${ }^{41} \mathrm{Al}$ igual que el National City Bank aconsejaba al gobierno el pago completo ${ }^{42} \mathrm{La}$ situación financiera de Estados Unidos había cambiado por el momento, ahora era imposible brindar ayuda financiera a Latinoamérica; Argentina debía resignar cualquier esperanza de colocar una nueva emisión en ese mercado. ${ }^{43}$ Según informaba la prensa internacional, Salaberry anunciaba que el préstamo por 50000000 sería cancelado al vencimiento, pero sin mencionar de dónde provendrían los fondos.

Frustradas las negociaciones en Nueva York, el ministro de Hacienda se dirigió a Londres a fin de obtener un préstamo que permitiera abonar las letras de tesorería que vencían en mayo en Londres y en Nueva York ${ }^{44}$ El acuerdo establecía que el gobierno británico realizaría un préstamo por 50000000 de dólares en Nueva York el día 15 de mayo de 1920 para abonar las letras pendientes (Departamento de Hacienda, 1920, p. CVIII). La fecha de vencimiento fue establecida para el 14 de enero de 1921 y el tipo de interés, de $5 \%$, libre de toda comisión o cargo. Puesto que el poder ejecutivo no contaba con la autorización del Congreso, se decidió que el Banco de la Nación tomara a su cargo el pago adeudado ${ }^{45}$ que luego se le reintegraría con el producto de la operación de crédito a realizarse con destino a las obras sanitarias en conformidad de las leyes 8889 y 9468 (Departamento de Hacienda, 1920, p. cVII). Dicha operación era posible por la fuerte posición acreedora que el Banco de la Nación Argentina tenía sobre Inglaterra y Francia como resultado de los préstamos de 1918-1919. De esta manera se pagó el empréstito angloamericano contratado en 1915, cerrando el ciclo de préstamos en la plaza de Nueva York.

\section{LaS Relaciones LondRes-Nueva York}

Desde finales del siglo xix Argentina había entablado un sólido vínculo financiero con Londres y principalmente con la casa Baring Brothers. Dicha casa no sólo tenía un agente propio en el país, sino que también había generado una relación financiera con la firma Ernesto Tornquist \& Cía., una empresa con fuertes contactos políticos y económicos, tanto en Argentina como en Europa, al menos desde 1897.

Por otra parte, en el mercado de Nueva York se carecía de experiencia en las cuestiones financieras sudamericanas (Rippy, 1950). Los préstamos externos que cotizaban en Nueva York eran porque los bancos estadunidenses habían formado parte de los sindicatos internacionales (Caroso

${ }^{39}$ Commercial and Financial Chronicles, 20 de marzo de 1920.

${ }^{40}$ The Economist, 1920, p. 1052.

${ }^{41}$ Commercial and Financial Chronicles, 1 de abril de 1920.

42 The Wall Street Journal, 15 de mayo de 1920.

${ }^{43}$ The Economist, 1920, p. 650.

${ }^{44}$ Commercial and Financial Chronicles, 17 de abril de 1920.

${ }^{45}$ El Banco de la Nación Argentina todavía era acreedor del gobierno inglés por los préstamos de 1918-1919. 
y Sylla, 1991). La única emisión argentina en Nueva York fue el Crédito Argentino Interno de 1909 puesto que la firma estadunidense J. P. Morgan \& Co. integró el sindicato europeo liderado por Baring y Morgan, Grenfell \& Co. (Regalsky, 2002). El mercado estadunidense estaba más interesado en Centroamérica por las posibilidades de negocios en la zona dada su cercanía, a diferencia de Sudamérica que había desarrollado una fuerte relación financiera con Europa (Marichal, 1989, pp. 170-172).

Las relaciones comerciales y financieras entre Argentina y Estados Unidos comenzaron con la apertura de las sucursales de los bancos estadunidenses en Buenos Aires en 1914. Las dos firmas financieras más importantes de Nueva York eran J. P. Morgan \& Co. (banco de inversión) y National City Bank (el banco comercial más dinámico). Según Parrini, sólo había entre ambos momentos ocasionales de cooperación (Parrini, 1969, p. 55) ${ }^{46}$ En rigor J. P. Morgan \& Co. se hallaba conectada con Londres a través de la casa Morgan \& Grenfell, y con París a través de Morgan-Harjes (Parrini, 1969, p. 56). Esta cooperación permitió a los europeos colocar títulos en Nueva York y a los estadunidenses en la plaza europea.

Siempre, según Parrini, mientras que J. P. Morgan \& Co. y sus asociados se oponían a rivalizar con la banca británica, el National City Bank mantenía una relación competitiva con los intereses exportadores y bancarios ingleses. Frank Vanderlip, William Rockefeller y el National City Bank buscaban desarrollar un sistema americano independiente. Por su parte, J. P. Morgan \& Co. sostenía que la cooperación bancaria angloamericana traería el mayor ingreso posible para ambas economías (Parrini, 1969, pp. 56-61). En 1915 se organizó la American International Corporation ${ }^{47}$ en cuyo directorio se encontraban representadas las tres principales firmas: Kuhn, Loeb \& Co., el National City Bank y la J. P. Morgan \& Co. La participación de J. P. Morgan evidencia que, a pesar de la cooperación con Inglaterra, dicha casa estaba interesada en un sistema americano independiente (Parrini, 1969, p. 63). Para Marichal, el National City Bank era el único banco estadunidense que estaba en condiciones de desafiar a los bancos europeos en Sudamérica (Marichal, 1989, p. 180).

En enero de 1915 el Bank of England prohibió las emisiones de capital para países que no formaran parte del imperio. Argentina obtuvo un permiso especial que le permitía emitir hasta 8 000000 de libras (monto que había sido adelantado en 1914). A pesar de esta decisión, Baring Brothers mantuvo a sus agentes en Buenos Aires con el objetivo de reforzar sus vínculos en el gobierno frente al avance estadunidense. En 1912 la firma Ernesto Tornquist \& Cía. había dejado de ser la representante de los intereses de la Baring en el país. La desvinculación ocurrió luego del fracaso en la negociación de un préstamo en 1911 ${ }^{48}$ La casa londinense sugirió entonces la incorporación de dos nuevos agentes: Manuel Augusto Montes de Oca e Hilary Howard Leng, de Leng, Roberts \& Co. La firma Tornquist se opuso a la incorporación de Leng porque lo consideraba como una pérdida de prestigio que debilitaría su posición 49 y ante la insistencia de Baring debió

\footnotetext{
${ }^{46}$ Sin embargo, la dupla Morgan-City había participado en el empréstito de 1909 y lo hubiera hecho nuevamente en 1911, si no fuera porque un consorcio franco-belga les ganó la operación (Regalsky, 2002, pp. 397-401). Se podría pensar que la asociación de ambas casas era bastante menos ocasional de lo que afirma Parrini.

${ }^{47} \mathrm{La}$ American International Corporation estaba conformada por J. P. Morgan \& Co., Guaranty Trust, Bankers Trust, National Bank of Commerce (los tres bajo el control de Morgan), First National Bank (afiliados a Morgan), National City Bank y Chase National Bank (aliados de Morgan) (Corey, 1930, p. 416).

${ }^{48}$ En 1911 se emitió el crédito argentino interno cuya colocación en la plaza europea fracasó y la pérdida tuvo que ser asumida por los bancos emisores, véase Regalsky (2002).

${ }^{49}$ El grupo Roberts como el Tornquist actuaron como bróker entre los inversores locales y extranjeros como por ejemplo J. P. Morgan, Baring Brothers y Rothschild. Véase Lluch y Salvaj (2014, p. 261).
} 
desvincularse. H. H. Leng y Manuel A. Montes de Oca se convirtieron en los representantes oficiales de Baring en Buenos Aires, con la asistencia de Everard Meynell, enviado desde Londres 50 Para Baring, si bien la firma Leng, Roberts \& Co. era pequeña, estaba conducida por hombres de carácter, de nacionalidad inglesa, que se podía confiar en que pondrían los intereses de la Baring en primer lugar (Ziegler, 1988, p. 309). Tanto el salario de Meynell como el de Montes de Oca eran abonados por Baring Brothers (Ziegler, 1988) ${ }^{51}$ La misión de Montes de Oca era reportar a Leng las opiniones de los ministros de Hacienda y de Obras Públicas y del presidente 52

Cuando en 1916, Carlos Alfredo Tornquist se dirigió a Nueva York, con vistas a establecer relaciones para un futuro negocio, no fue tomado a la ligera por la Baring, puesto que consideraba que cualquier relación que se estableciera en Nueva York tendría un impacto en el consorcio angloamericano.

La actuación de J. P. Morgan tanto para los intereses estadunidenses como para los ingleses, se puede observar en la profusa correspondencia disponible entre J. P. Morgan \& Co. y MorganGrenfell \& Co. a lo largo del periodo de la guerra. Para la casa estadunidense, si bien los asuntos de Buenos Aires eran atribución de Baring Brothers y del consorcio londinense, las solicitudes de préstamos del gobierno argentino en Nueva York hacían necesario comunicar al grupo europeo esta situación con el fin de evitar malos entendidos 53 Por otro lado, la tesis de Flandreau (2015) respecto de que el mercado estadunidense trasplantó el sistema de sindicato europeo se puede comprobar en la conformación del sindicato liderado por la J. P. Morgan llamado American Group. En 1916 se creó el South American Group, que contaba con la participación de la J. P. Morgan \& Co., el National City Bank, Kuhn, Loeb \& Co. y el First National Bank de Boston. El objetivo de dicha organización era concentrar y retener para sí todas las negociaciones en el mercado financiero estadunidense con la región.

Para el periodo comprendido en este trabajo -y para el caso argentino- no se observó una rivalidad o competencia entre el National City Bank y la J. P. Morgan \& Co., sino más bien una cooperación entre ambas, junto con el sindicato londinense, frente a otras casas financieras estadunidenses como, por ejemplo, el Guaranty Trust Co. y Hallgarten \& Co. Estas dos últimas habrían entablado negociaciones con el gobierno argentino, mientras este se encontraba negociando con el South American Group un préstamo por 15000000 de dólares a principios de 1916. Estas firmas entraron en competencia con el grupo y Hallgarten aumentó la oferta a 18500000 dólares al gobierno 51 consorcio al enterarse de que el gobierno se encontraba negociando de manera simultánea con otros banqueros decidió retirarse de las negociaciones. Mientras que el First National Bank decidió retirarse del South American Group, el Guaranty Trust llegó a un entendimiento con el grupo liderado por J. P. Morgan \& Co. y se incorporó al sindicato 55

\footnotetext{
${ }^{50}$ La firma Roberts, Leng \& Co. en 1936 se renombraría Roberts, Meynell \& Co. y sirvió como representante de la J. P. Morgan \& Co. en Argentina.

${ }^{51}$ La Baring Brothers le pagaba a Montes de Oca una comisión de 1000 libras. Carta de Gaspar Farrer a James Stillman del 14 de diciembre de 1916. Archivo Baring Brothers (en adelante ABB), carpeta 200076.

${ }^{52}$ Memorándum conversación con H. H. Leng, 15 de agosto de 1912. ABB, carpeta 200100.

${ }^{53}$ Carta de J. P. Morgan \& Co. a Morgan-Grenfell \& Co., 9 de mayo de 1916. ABB, carpeta 200076.

${ }^{54}$ Memorándum, 23 de mayo de 1916. ABB, carpeta 200076

${ }^{55}$ Memorándum, 23 de mayo de 1916 y carta de Alfred Mildmay a H. H. Leng, 20 de junio de 1916. ABB, carpeta 200076.
} 
El representante del South American Group en Argentina era John Allen, del National City Bank, quien, de acuerdo con la correspondencia, no tuvo una buena relación con el ministro de Hacienda Salaberry. Este último le habría comunicado a Leng que las relaciones con el grupo estadunidense y con Allen habían sido poco confortables, desafortunadas y tensas ${ }^{56}$ El ministro comentaba que no entendía los métodos de Nueva York y que un poco más de cortesía no habría estado mal ${ }^{57}$ Por su parte, el National City y Allen reconocían que eran nuevos en el negocio y que tenían poco personal y equipamiento para tener éxito en las negociaciones ${ }^{58}$ Los banqueros estadunidenses habían solicitado que la emisión de 250000000 de pesos oro, presentada a finales de 1916, estuviera garantizada por la creación de nuevos impuestos o por las rentas de la Aduana. Para Leng, esto era un problema, puesto que el gobierno nacional no iba a acceder a una cláusula que, ya a principios de 1900, había suscitado una fuerte reacción popular ${ }^{59}$ Para Baring esto se debía al desconocimiento de los banqueros estadunidenses y consideraba una pérdida de tiempo presionar para que el ministro de Hacienda aceptara la incorporación de la garantía. Tanto los banqueros estadunidenses como Leng, esperaban que los contactos y la influencia de Montes de Oca, tanto en los miembros como en la Comisión de Finanzas, tuvieran sus frutos y que la ley fuera sancionada.

En este contexto debe entenderse la solicitud de J. P. Morgan \& Co. a Baring Brothers para que sus agentes, Leng y Montes de Oca, trabajaran para el South American Group 60 Esto se debía a que habían tenido éxito en el pasado ganándose la confianza de los sucesivos ministros argentinos. ${ }^{61}$ Ambos aceptaron la oferta, y Leng ahora debía reportar directamente a Allen y al South American Group durante la guerra ${ }^{62}$ Finalmente, Allen se retiró de las negociaciones, las cuales quedaron bajo la conducción de Leng. 63

Los nuevos agentes debían transmitir que la dignidad y los intereses materiales del gobierno serían mejor servidos por un grupo con poder y representativo de los principales actores de Estados Unidos, que serían los más capaces de infundir confianza en el crédito argentino, en una comunidad cuya inexperiencia en inversiones internacionales la hacía depender de la guía de los banqueros ${ }^{64}$ El sindicato londinense afirmaba que durante muchos años se habían esforzado por prevenir el daño por los gastos excesivos del gobierno argentino y ahora que los bancos europeos habían quedado fuera del negocio era más importante que nunca que el grupo estadunidense tomara a su cargo el control de los gastos ${ }^{65}$ Tanto el consorcio europeo como el estadunidense consideraban que el gobierno argentino negociaba con grupos irresponsables (en relación con Hallgarten) sin darse cuenta de que el sindicato podía lidiar mejor con los fuertes vencimientos que tenía el país. 6 El grupo estadunidense sugería firmeza, puesto que el gobierno no se había dado

${ }^{56}$ Carta de H. H. Leng a Gaspar Farrer, 4 de enero de 1917. ABB, carpeta 200076

${ }^{57}$ Carta de H. H. Leng a Alfred Mildmay, 7 de febrero de 1917. ABB, carpeta 200076

${ }^{58}$ Carta de Alfred Mildmay a H. H. Leng, 13 de diciembre de 1916 . ABB, carpeta 200076

${ }^{59} \mathrm{El}$ proyecto de unificación de la deuda externa pública presentado en junio de 1901 autorizaba que el empréstito a emitirse contara con la garantía de las rentas de la Aduana. Véanse Rodjkind (2011) y Vence (2016).

${ }^{60}$ Carta de Baring Brothers a H. H. Leng, 11 de diciembre de 1916. ABB, carpeta 200076

${ }^{61}$ Carta James Stillman, 19 de octubre de 1916. ABB, carpeta 200076

${ }^{62}$ Carta de James Stillman a Gaspar Farrer, 1 de diciembre de 1916. ABB, carpeta 200076

${ }^{63}$ Carta de H. H. Leng a Alfred Mildmay, 24 de enero de 1917. ABB, carpeta 200076

${ }^{64}$ Carta de Baring Brothers a H. H. Leng, 11 de diciembre de 1916. ABB, carpeta 200076

${ }^{65}$ Carta de Morgan, Grenfell \& Co. al J. P. Morgan \& Co., 1 de noviembre de 1916. ABB, carpeta 200076

${ }^{66}$ Carta de J. P. Morgan \& Co. a Morgan, Grenfell \& Co., 13 de noviembre de 1916. ABB, carpeta 200076. 
cuenta que estando la casa Baring fuera del negocio era imposible conseguir grandes cantidades de dinero. ${ }^{67} \mathrm{El}$ consorcio estadunidense quería evitar que las casas más chicas se quedaran con el negocio ofreciendo mejores condiciones, como ocurrió en las negociaciones de 1911.

Esto permite comprobar, para el caso argentino, lo sugerido por la historiografía sobre la importancia que las casas bancarias le otorgaban al prestigio y la reputación (Flandreau y Flores, 2010; Flandreau, Gaillard y Panizza, 2011), del mismo modo que los intermediarios financieros en el éxito de la emisión (Flores, 2012). Los bancos actuaban como consejeros de los inversionistas al contar con una relación directa con los gobiernos, por lo que el prestigio del banco emisor era la garantía para el inversor. En este sentido, Stillman, presidente del National City Bank, reconocía que uno de los problemas que debieron enfrentar fue que varias firmas negociaban directamente con el gobierno argentino por lo que sugería recomendar al gobierno confiar sus negociaciones a un grupo únicamente, el de Nueva York 68

Ante el vencimiento del préstamo de Hallgarten el gobierno esperaba poder renovarlo. Por su parte, el South American Group pensó en enviar a dos representes de primera clase para fortalecer los lazos con Argentina ${ }^{69}$ Los informes que llegaban al consorcio estadunidense y londinense respecto de si el préstamo de Hallgarten sería renovado o pagado al vencimiento eran contradictorios. Algunos hacían referencia a que se renovaría 70 mientras que otros notificaban que las negociaciones se habían roto ${ }^{71}$ A mediados de febrero se conoció que Hallgarten había rechazado la renovación. El gobierno se sintió engañado, porque hasta el último momento la firma estadunidense de manera verbal había asegurado la renovación 72 dejándolo en una rara situación. El presidente del Banco de la Nación Argentina, Manuel de Iriondo 73 se entrevistó con Allen -a pedido del ministro de Hacienda- para la consecución de un adelanto en vista del fracaso de la renovación. Allen respondió que el grupo no participaría de la operación 74 El consorcio estadunidense esperaba que la caída de Hallgarten fuera una lección objetiva para el gobierno sobre la futilidad de negociar con casas bancarias de segundo orden, ${ }^{75}$ y que comprendiera que el mercado de Estados Unidos era distinto al europeo, puesto que su público estaba poco educado en relación con los negocios sudamericanos y eso complicaba la colocación de deuda soberana ${ }^{76}$ Entre abril y mayo de 1917 vencían las notas emitidas con el Guaranty Trust. El gobierno intentó un acercamiento con el grupo de Nueva York para la renovación de los vencimientos y el South American Group se mostró dispuesto y la fecha de pago se estableció para el mes de octubre (véase cuadro 3).

Esta renovación debe entenderse en el contexto del tratado de venta de trigo a los aliados de 1918. Entre julio y noviembre de 1917 se llevaron a cabo las reuniones con las autoridades británicas y francesas respecto de la compra de trigo y otros cereales. Robert Lansing 77 instruyó

${ }^{67}$ Carta de Thomas Lamont a Morgan, Grenfell \& Co., 14 de noviembre de 1916. ABB, carpeta 200076.

${ }^{68}$ Carta de James Stillman a Gaspar Farrer, 1 de diciembre de 1916. ABB, carpeta 200076.

${ }^{69}$ Carta de J. P. Morgan \& Co. a Morgan, Grenfell \& Co, 3 de febrero de 1917. ABB, carpeta 200076.

${ }^{70}$ Carta de H. H. Leng a Baring Brothers, 3 de febrero de 1917. ABB, carpeta 200076.

${ }^{71}$ Carta de Gaspar Farrer a H. H. Leng, 1 de febrero de 1917. ABB, carpeta 200076.

${ }^{72}$ Carta de H. H. Leng a Baring Brothers, 14 de febrero de 1917. ABB, carpeta 200076.

${ }^{73}$ Manuel María de Iriondo presidió el Banco de la Nación Argentina entre 1910 y 1918.

${ }^{74}$ Carta de Alfred Mildmay a H. H. Leng, 16 de febrero de 1917. ABB, carpeta 200076.

${ }^{75}$ Carta de Gaspar Farrer a H. H. Leng, 20 de febrero de 1917. ABB, carpeta 200076.

${ }^{76}$ Carta de Gaspar Farrer a H. H. Leng, 1 de febrero de 1917. ABB, carpeta 200076.

${ }^{77}$ Robert Lansing se desempeñó como secretario de Estado de Estados Unidos entre 1915 y 1920. 
a Stimson a que trabajara de manera conjunta con los representantes de las misiones europeas. A cambio Argentina debía ofrecer un crédito a los aliados para concertar el acuerdo (Peterson, 1964, p. 316). En diciembre de 1917, frente a las exigencias argentinas en las negociaciones, los representantes de los aliados amenazaron con hacer públicas las negociaciones y que, en caso de no arribarse a un acuerdo, se verían obligados a interrumpir la compra de productos argentinos. A finales de mes, el gobierno de Yrigoyen aceptó la propuesta frente a la presión estadunidens $€^{78}$ y el acta fue firmada en enero de 1918 ${ }^{79}$ La negociación demostró el liderazgo de Estados Unidos sobre Europa.

En 1920, cuando se estaba por producir el vencimiento del préstamo angloamericano de 1915 por 50000000 de dólares, el gobierno argentino a través de su encargado de negocios en Londres, Jacinto L. Villegas, consultó a Baring sobre la posibilidad de que el gobierno británico le adelantara a Argentina los fondos necesarios para cubrir el vencimiento ${ }^{80}$ Por su parte, Leng consultó a Baring qué curso de acción le recomendaban tomar al gobierno argentino, y sugirió que las negociaciones debían ser pospuestas hasta el mes de abril de $1920{ }^{81}$ Sin embargo, las conversaciones se iniciaron en el mes de marzo luego de que el ministro Salaberry no obtuviera la renovación del préstamo en Nueva York. El ministro aducía que la sugerencia habría provenido de los bancos estadunidenses, pero que el gobierno nacional podría disponer de los fondos para levantar la obligación El 19 de abril de 1920 el contrato fue aceptado por Londres y Buenos Aires ${ }^{83}$ Vale la pena destacar que los fondos terminaron siendo aportados por el Banco de la Nación Argentina, puesto que el poder ejecutivo carecía de la indispensable autorización legislativa.

En 1921, el grupo J. P. Morgan decidió disolver el South American Group. Para la casa estadunidense los gobiernos latinoamericanos habían evitado ajustes dolorosos. Los gobiernos en principio decían que sí a todo, pero cuando alguien les ofrecía un préstamo a una tasa más favorable de la que podían conseguir con el grupo, abandonaban todos los planes para fortalecer su crédito. Cuestión similar planteó Otto Kuhn, de Kuhn, Loeb \& Co., en las audiencias del Congreso de Estados Unidos de 1932. Allí, planteó que lo usual era que se estableciera una relación entre el banco y el país. Pero varios países, entre ellos Argentina, iban de un banquero a otro (Congress, 1932). Por su parte, Leng le escribía a Gaspar Farrer comentándole que la reciente experiencia del gobierno en préstamos de corto plazo habría sido una lección suficiente para tentar a la fortuna de nuevo en la misma forma. Y agregaba, "lamentaríamos ver las finanzas argentinas temporalmente en manos de Kuhn o de cualquiera fuera de nuestro grupo" ${ }^{84}$ Por su parte, J. P. Morgan le decía a Morgan-Grenfell: "esperamos que Leng le pueda mostrar al gobierno las ventajas de

\footnotetext{
${ }^{78}$ Los estadunidenses amenazaron al gobierno argentino con no otorgar licencias para la venta de carbón, maquinarias agrícolas y, por otro lado, puesto que Argentina buscaba refinanciar los préstamos que vencían en 1917 en Nueva York, el gobierno británico habría sugerido que la renovación fuera bajo la condición de la exportación de granos a los aliados (Gravil, 1977, p. 73).

${ }^{79}$ Sobre las negociaciones, véanse Peterson (1964), Gravil (1977) y Weinmann (1994).

${ }^{80}$ Las negociaciones con el gobierno británico en 1920 deben entenderse en el contexto del vencimiento del préstamo de trigo a los aliados contratado en 1918.

${ }^{81}$ Carta de H. H. Leng a Baring Brothers, 24 de julio de 1919. ABB, Argentine Government Affairs, carpeta 200290.

${ }^{82}$ Carta de Jacinto Villegas a lord Revelstoke, 22 de marzo de 1920. ABB, Argentine Government Affairs, carpeta 200290 .

${ }^{83}$ Telegrama de Baring Brothers al presidente de la República Argentina, 19 de abril de 1920. ABB, Argentine Government Affairs, 200290.

${ }^{84}$ Carta de H. H. Leng a Gaspar Farrer, 12 de agosto de 1921. ABB, Argentine Government Affairs, carpeta 200291.
} 
reasumir relaciones con nosotros y ustedes" ${ }^{85}$ Estas dos frases hacen referencia a dos cuestiones que seguirán presentes en la primera mitad de la década de 1920. La primera era la relación con los outsiders, las firmas bancarias estadunidenses de menor envergadura, que, según ellos, les arrebatan los negocios. La segunda concernía a la vigencia de la relación angloamericana en el grupo City-Morgan.

\section{Conclusiones}

El estallido de la primera guerra mundial en 1914 tuvo una fuerte repercusión en las condiciones de financiamiento del gobierno argentino. De un lado, el aumento vertiginoso del déficit fiscal por la caída de la recaudación y, del otro, el cierre de los tradicionales mercados europeos para las emisiones de largo plazo, pusieron al gobierno argentino en la disyuntiva de buscar nuevas fuentes de recursos a través del aumento de su deuda flotante interna y exterior. Si la primera pudo efectuarse a través de los bancos locales, y notablemente, del Banco de la Nación Argentina, la consecución de la segunda llevó tempranamente a negociaciones para acceder al único mercado financiero externo entonces disponible, el de Nueva York.

Estas negociaciones, que formaron parte inicialmente de un acercamiento con Estados Unidos también en el plano comercial y diplomático, habrían de tener un giro a fines de 1916 con el ascenso a la presidencia argentina de Hipólito Yrigoyen, celoso defensor de la postura de neutralidad argentina, y más aún cuando la entrada de Estados Unidos a la guerra supuso el incremento de las presiones para que Argentina se incorporase al bando aliado.

En cualquier caso, el desplazamiento del centro financiero internacional a Nueva York no implicó innovar respecto del sistema de negociación y el accionar de los intermediarios financieros mientras Londres era hegemónico. Sí merece mención la crisis que hubo en la intermediación local al abandonar la firma Tornquist la tradicional representación de los intereses del grupo Baring, que de todos modos halló nuevos agentes mejor vinculados con las esferas oficiales que la nueva banca estadunidense. La formación de un South American Group por los establecimientos estadunidenses mejor posicionados, y su colaboración con la banca inglesa fue uno de sus corolarios, al igual que la preocupación frente a la participación en el negocio de jugadores de menor porte, que pudieron en 1916 obtener una tajada del mercado ofreciendo mejores condiciones al gobierno argentino.

La situación pretendió ser encarada por el flamante gobierno radical a través de una consolidación de la deuda y la emisión de títulos de largo plazo sobre el mercado estadunidense. Las dificultades para hacer aprobar internamente dicha iniciativa, y el desmejoramiento de las condiciones para la misma cuando Estados Unidos ingresó a la guerra, llevaron finalmente a una reversión de las operaciones de endeudamiento externo, que serían reemplazadas hasta 1920 por el financiamiento del sector público en el mercado interno y aun el préstamo de fuertes cantidades a los países previamente acreedores de Argentina. La crisis de 1920 clausuraría esa reversión abriendo un nuevo ciclo de endeudamiento externo argentino que se proyectaría durante toda la década de 1920, y por plantearse en un contexto bien diferente, deberá ser objeto de futuras investigaciones.

\footnotetext{
${ }^{85}$ Carta de J. P. Morgan \& Co. a Morgan, Grenfell \& Co., 19 de agosto de 1921. ABB, Argentine Government Affairs, carpeta 200291.
} 


\section{LISTA DE REFERENCIAS}

Albert, B. (1988). South America and the First World War: The Impact of the War on Brazil, Argentina, Peru and Chile. Cambridge: Cambridge University Press. Dor: 10.1017/CBO9780511529184

Caroso, V. y Sylla, R. (1991). US banks in international finance. En R. E. Cameron, V. I. BovyKIN y B. V. ANANICH (Eds.), International banking, 1870-1914 (pp. 48-72). New York: Oxford University Press. Recuperado de http://site.ebrary.com/id/10087135

Congress US. (1932). Sale of foreign bonds or securities in the Unites States, hearings before the Committee on Finance Unites States Senate.

Corey, L. (1930). The House of Morgan: A social biography of the masters of money. Nueva York: G. Howard Watt.

Cortés, R. (2008). The political economy of Argentina in the twentieth century. Cambridge: Cambridge University Press. Recuperado de http://site.ebrary.com/lib/alltitles/docDetail.action?docID= 10279728

Denne, P. A. (2009). On the far Western Front: Britain's First World War in South America. Manchester: Manchester University Press.

Dehne, P. A. (2011). Britain's global war and Argentine neutrality. En J. Den Hertog y S. KruiZINGA (eds.), Caught in the middle: neutrals, neutrality, and the First World War (pp. 67-83). Amsterdam: Aksant.

Della Paolera, G. y Taylor, A. (1999). Internal Versus External Convertibility and DevelopingCountry FinancialCrises: Lessons from the Argentine Bank Bailout of the 1930's (No. w7386). Cambridge, MA: National Bureau of Economic Research. Dor: 10.3386/w7386

Della Paolera, G. y Taylor, A. M. (2003). Tensando el ancla: la caja de conversión argentina y la búsqueda de la estabilidad macroeconómica, 1880 - 1935 (1. ed. en español). Buenos Aires: Fondo de Cultura Económica de Argentina.

Departamento de Hacienda. Argentina (1917/1920). Memoria del Departamento de Hacienda. Buenos Aires: Talleres Gráficos Argentinos.

Di Tella, G. y Zymelman, M. (1967). Etapas del desarrollo económico argentino. Buenos Aires: Eudeba.

DíAz, C. (1975). Ensayos sobre la historia económica argentina. Buenos Aires: Amorrortu.

Flandreau, M. (2015). Anatomy of a regime change: Underwriters' reputation, new deal financial acts and the collapse of international capital market (1920-1935). Presentado en Financial Systems and Economic Growth Conference in Honor of Richard Sylla, Nueva York: New York University. Recuperado de https://bit.ly/2yYFB69

Flandreau, M. y Flores, J. (2011). Bondholders vs. bond-sellers? Investment bank and conditionality lending in the London market for foreign government debt 1815-1913 (EHEs Working Papers in Economic History No. 2). European Historical Economics Society. Recuperado de http:// www.ehes.org/EHES_No2.pdf

Flandreau, M., Gaillard, N. y Panizza, U. (2010). Conflicts of Interest, Reputation, and the Interwar Debt Crisis: Banksters or Bad Luck? (No. HEID Working paper 02/2010). Ginebra: The Graduate Institute. Recuperado de http://www.ssrn.com/abstract=1588031

Flores, J. H. (2012). Fundamentos económicos, fallos de mercado y exportación de capitales: América Latina y el mercado de Londres, 1880-1913. América Latina en la Historia Económica, 19(3), 5-30. DoI: 10.18232 /alhe.v19i3.527 
Ford, A. (1966). El patrón oro 1880-1914: Gran Bretaña y Argentina. Buenos Aires: Instituto Torcuato Di Tella.

Gerchunoff, P. y Aguirre, H. (2006). La economía argentina entre la gran guerra y la gran depresión. Buenos Aires: Comisión Económica para América Latina y el Caribe. Recuperado de http: //www.cepal.org/publicaciones/Buenosaires/8/LCL2538P/DocSerie32fin.pdf

GraviL, R. (1977). The Anglo-Argentine Connection and the War of 1914-1918. Journal of Latin American Studies, 9(1), 59-89. DoI: 10.1017/S0022216X00019337

GraviL, R. (1985). The Anglo-Argentine connection, 1900-1939. Boulder: Westview Press.

Lluch, A. y SALVAJ, E. (2014). Longitudinal study of interlocking directorates in Argentina and foreign firms' integration into local capitalism (1923-2000). En T. David y G. Westerhuis (eds.), The power of corporate networks: a comparative and historical perspective (pp. 257-275). Nueva York: Routledge/Taylor \& Francis Group.

Marichal, C. (1989). A century of debt crises in Latin America: from independence to the Great Depression, 1820-1930. Princeton: Princeton University Press.

Marichal, C. y Gambi, T. (eds.). (2017). Historia bancaria y monetaria de América Latina (siglos XIX y XX): nuevas perspectivas. Santander: Editorial de la Universidad de Cantabria/Universidade Federal de Alfenas.

Nakamura, L. y Zarazaga, C. (1997). Economic growth in Argentina in the period 1900-1930: some evidence from the stock returns (No. Working Paper 97-22). Filadelfia: Federal Reserve Bank of Philadelphia.

Nakamura, L. y Zarazaga, C. (2001). Banking and finance in Argentina in the period 1900-1935 (No. Working Paper 01-07). Filadelfia: Federal Reserve Bank of Philadelphia.

Parrini, C. P. (1969). Heir to empire United States economic diplomacy, 1916-1923. Pittsburgh: University of Pittsburg Press. Recuperado de http://digital.library.pitt.edu/cgi-bin/t/text/text-idx: idno=31735057895017; view=toc; $=$ pittpress

Peters, H. E. (1934). The foreign debt of the Argentine Republic. Baltimore: The John Hopkins Press.

Peterson, H. (1964). Argentina and the United States, 1810-1960. Nueva York: State University of New York.

Phelps, V. (1938). The international economic position of Argentina. Filadelfia: University of Pennsylvania Press/ Oxford University Press.

Rayes, A. (2014). Los destinos de las exportaciones y la neutralidad argentina durante la primera guerra mundial, (42), 31-52.

Regalsky, A. (2002). Mercados, inversores y elites. Las inversiones francesas en Argentina 1880-1914. Buenos Aires: Eduntref.

Regalsky, A. (2018). En los preámbulos de la banca central: el sistema monetario y bancario en las primeras tres décadas del siglo y el papel del Banco de la Nación Argentina. En M. Rougier y F. Semper (eds.), Historia necesaria del Banco Central de la República Argentina. Buenos Aires: Lenguaje Claro.

Regalsky, A. y Iglesias, M. (2015). Banca pública, banca privada y crisis: el Banco de la Nación Argentina como prestamista de última instancia entre la primera guerra mundial y la posguerra. Ensayos Económicos, 72, 103-193.

Regalsky, A. M. y Salerno, E. (2003). Las finanzas públicas en los tiempos del radicalismo: ferrocarriles, obras públicas y endeudamiento 1916-1928. Presentado en Terceras Jornadas de Historia Económica, Montevideo: Asociación Uruguaya de Historia Económica. 
Regalsky, A. M. y Salerno, E. (2009). Financiamiento e Inversión Pública en la Argentina en un Periodo de Transición, 1900-1935. Un Enfoque General y Dos Estudios de Caso. Revista de Historia Económica/Journal of Iberian and Latin American Economic History, 27(2), 205-246. DOI: $10.1017 / \mathrm{S} 0212610900000756$

Rinke, S. (2017). Latin America and the First World War. Cambridge: Cambridge University Press. DOI: $10.1017 / 9781316411735$

RIPPy, F. (1950). A bond-selling extravaganza of the 1920's. Journal of Business of the University of Chicago, 23(4), 238-247.

RodjKIND, I. (2011). Una explosión ruidosa de indignación pública: deuda, honor nacional y protesta política en el 900. En M. Z. Lobato (ed.), Buenos Aires. Manifestaciones, fiestas y rituales en el siglo XX. Buenos Aires: Biblos.

Siepe, R. (1992). Yrigoyen, la Primera Guerra Mundial y las relaciones económicas. Buenos Aires: Centro Editor de América Latina.

SoARes, C. (1922). Economía y finanzas de la nación argentina. Buenos Aires: Imp. Rodriguez Giles.

Stallings, B. (1987). Banker to the Third World: U.S. portfolio investment in Latin America, 19001986. Berkeley: University of California Press.

ТАто, M. I. (2008). La disputa por la argentinidad. Rupturistas y neutralistas durante la primera guerra mundial. Temas de Historia Argentina y Americana, 13, 227-250.

TAYLOR, A. (1997). Argentina and the World Capital Market: Saving, Investment, and International Capital Mobility in the Twentieth Century (No. w6302). Cambridge: National Bureau of Economic Research. DOI: $10.3386 / \mathrm{w} 6302$

Taylor, A. M. (1992). External Dependence, Demographic Burdens, and Argentine Economic Decline After the Belle Époque. The Journal of Economic History, 52(4), 907-936. Dor: 10. 1017/S0022050700011955

Tulchin, J. (1990). Argentina y Estados Unidos. Historia de una desconfianza. Buenos Aires: Planeta.

VÁzQuez, V. (1978). Crisis y retraso. Argentina y la economía internacional entre las dos guerras. Buenos Aires: Eudeba.

Vence, A. (2016). La trama política detrás de la crisis de 1901: el rol de Carlos Pellegrini. Revista Cambios y Permanencias, 7, 240-279.

Weinmann, R. (1994). Argentina en la primera guerra mundial: neutralidad, transición política y continuismo económico. Buenos Aires: Biblos.

ZIEGLER, P. (1988). The sixth great power. A history of one of the greatest of all banking families, the House of Baring. Nueva York: Knopf.

Archivos

ABB Archivo Baring Brothers, Londres, Inglaterra.

Hemerografía

The Economist, Londres, Inglaterra.

The Wall Street Journal, Nueva York, Estados Unidos.

Commercial and Financial Chronicles, Nueva York, Estados Unidos.

Diario de Sesiones de la Cámara de Diputados, Buenos Aires, Argentina.

New York Tribune, Nueva York, Estados Unidos.

The Sun, Nueva York, Estados Unidos. 